\title{
Introducing a learner response system to pre-service education students: Increasing student
} engagement

\author{
Chris Campbell and Sue Monk
}

\section{Biographies of authors}

Chris Campbell, School of Education, The University of Queensland, Brisbane, 4072, QLD, Australia. Tel: +61 733656215 Fax: +61.73365 7199 Email: chris.campbell@uq.edu.au

Sue Monk, School of Education, The University of Queensland, Brisbane, 4072, QLD, Australia. Tel: +61733656508 Fax: +61.733657199 Email: s.monk@uq.edu.au

Chris Campbell is a lecturer in ICT Education in the School of Education and lecturers both pre-service and in-service teachers in the use of learning technologies in their teaching. Her research interests include the use of technologies to enhance learning, in particular mobile devices and interactive whiteboard use in both primary and secondary schools.

Sue Monk researches in the areas of social justice in education, issues of access and equity for marginalized students. Sue teaches in the Arts curriculum area for pre-service teachers. Her background is in ethnomusicology and Latin American studies and her research interests include the Arts as an educational tool, the educational approaches of Paulo Freire.

\begin{abstract}
Described in this study is a learner response system (clickers) used with first year undergraduate students in a small group setting. The aim of the project was to address issues faced by us all as we seek to improve class participation, as well as engage students in lectures and tutorials throughout the course. Data collection for this case study incorporated diary entries by the lecturer and student responses to the use of clickers and reflects both the course coordinator's journey through the process of introducing this new technology and changing students' responses as they engage with this technology. The article reports on the positive results particularly in relation to increased potential for clickers to be used as a teaching and learning tool. The significance of this study, however, lies in the recognition that pedagogical approaches need to be taken into consideration when planning for effective use of clickers as a tool for engaging students.
\end{abstract}

\section{Keywords}

Learner response system, clickers, pre-service education students, student engagement, technology implementation

\section{Current challenges for teaching and learning in the university environment}

Whilst lecturers seek to engage undergraduate students in their classes, there is, nevertheless, a significant challenge when teaching courses with large numbers of enrolments. The university teaching environment requires lecturers to be up-to-date with technology - what to use, how to use it, the rationale for using it - and be totally convinced of its merits. Increasingly there are technologies available that are able to assist with providing more flexibility in delivering course content (such as the Lectopia lecture recording system and Blackboard) but these do not necessarily engage all students. Often it is a fine balance to maintain student engagement when there is no longer a necessity for students to be physically present at a lecture if they can watch the recording at any time after the lecture. The concern over losing face-to-face contact with students (Massoud, et al., 2011), along with other debates around pedagogical practices such as how to assess student participation in tutorials and lectures versus an 
online 'bulletin board approach' (Sweeney, et al., 2004) makes for a controversial space to discuss the relationship between new technologies and student engagement. Compounding the issue, many students are confident users of social media technologies, and thus the challenges of maintaining engagement and monitoring their progress throughout the course of traditional, technology-poor lecture approaches can quickly impact upon their level of engagement and success in the early part of their studies.

There are many factors that determine whether academics will incorporate new technologies into the planning of their courses. Notwithstanding the time needed for professional development, there may be initial reluctance to trial new technologies with a new cohort of students, particularly in a first-year course where the academic has not had time to develop background knowledge about the students or a rapport with the class. These courses often have large numbers of students who, at an early stage in their higher education studies, can be reluctant to participate in class discussions. However, it is precisely because these large cohorts of students need to be able to quickly engage with both the course requirements as well as a new learning environment that there is an urgency to look for effective tools to enhance student participation.

\section{Clickers in higher education}

Learner response systems (clickers) can also be called 'clickers' or 'student response systems' as well as a plethora of other names that denote them. They can be used to help start discussions and as tools for developing both formative and summative assessment tasks in class. Students can also use the devices to assess peers when presentations and the like are given in class (Premkumar and Coupal, 2008). They can provide valuable feedback to the teacher in a variety of ways. For example, the teacher can learn if the students understand a particular concept, whether they are engaged in class or feel the topic is valuable. Even though a large variety of questions can be created it is still important to ensure that pedagogy is the focus of the class (Premkumar and Coupal, 2008). Massingham and Herrington's (2006) study reports that the most influential factors of student attitudes are actually the teaching processes used in class, for example, constructivist instead of transmissive, with constructivist learning being that students learn through active engagement while constructing knowledge. Their explanation that the teaching and the learning environment has shifted from the "teacher-centred instruction, information, passive and individual learning" to "more emphasis... on approaches that involve problem solving, collaboration, discussion, authentic contexts, and action" reminds those of us working in university environments of the need to investigate new ways of engaging our students (p. 85).

Clickers are becoming a regularly integrated component of lecturing in university classrooms. As lecturers increasingly incorporate this emerging technology into their presentation approach, formal guidelines and methodologies could assist in optimising and documenting its successful use whereby practitioners recognize the scope of the technology and identify its role in modern pedagogy (Beatty and Gerace, 2009; Dallaire, 2011; Gray and Steer 2012; Laxman, 2011; Mayer et al., 2009; Powell et. al, 2011; Trees and Jackson, 2007). There is a significant body of literature that surrounds the implementation and use of clickers in various higher education contexts (for example: Milner-Bolotin et al., 2010; Barnett, 2006; Koenig, 2010; Hall et al., 2005; Caldwell, 2007; Strasser, 2010). In a study of first year physics students, researchers defined 'clicker effectiveness' as student perception that using clickers helped them to "stay engaged in class, understand the material, get continuous formative feedback on their progress, clarify difficult concepts, and reflect on their own learning" (Milner-Bolotin et al., 2010: 16). Other studies support student engagement is improved through the use of clickers (Bachman and Bachman, 2011; Blood and Neel, 2008; Strasser, 2010).

Students have also reported enjoying the interactivity in class afforded by the use of clickers (Barnett, 2006). A study by Murphy et al. (2010), reports that students in a chemistry course had improved their learning as a result of using the clickers in class. This study used a quasi-experimental design and involved the students with the clickers answering two to four questions per lecture. Final assessment results for the course indicated that these students received $1 / 3$ of a grade point higher than the no clicker control group. This suggests that the clicker group were more cogitatively, or more aware about knowing, and engaged in the lectures.

A quantitative study on undergraduate Operations Management courses investigated how the use of clickers affected learning outcomes (Yourstone et al., 2008). The results suggest that the use of clickers 
"can have an impact on student learning as measured by test scores" (Yourstone et al., 2008, 85). They go on to comment that it may not actually be the clicker technology that is responsible for the improved learning outcomes but the actual immediate feedback provided to the students through the use of the clickers. Much of the literature focuses primarily on the extent to which clickers enhance students' interest by providing a mechanism for interaction and participation, thereby creating potential for improved student performance.

However, implementation of this technology or any other has not been without problems. These include problems with students registering the clickers for use with the group and the clickers not always working properly (Barnett, 2006). While there can be some implementation problems (Hoekstra and Mollborn, 2011) it is worth working through the challenges as the literature and our long use of this technology has demonstrated the value and benefit of the use of clickers.

As outlined above, there is a substantial body of research which outlines the benefits of using clicker technology in higher education teaching and learning environments. This research suggests that the use of clickers may act as a powerful catalyst to transform pedagogical practices, facilitating a move from teacher-centered to student-centered conceptions and approaches (Kolikant et al., 2010). However, there is little research that details the process by which the lecturer learns how to incorporate the technology in a way that satisfactorily and effectively complements their pedagogical approach, thereby helping them commit to the rationale for incorporating this technology.

\section{Using clickers to enhance learning}

Caldwell (2007) suggests that the use of clickers in class offers flexibility in learning as they can be used effectively in both lectures and tutorials and can be used with many different styles of questions. Trees and Jackson's research of 1500 undergraduates enrolled in seven large courses across three university departments, has been well reported and they suggest that there are a number of factors contributing to students' positive reception to using clickers in class. These factors include the view that traditional lecture styles, such as 'passive listening', are not the best way to teach large classes; another is students' own desire to be engaged and involved in the class. Students in the study also reported they valued the feedback the use of clickers was able to provide (Trees and Jackson, 2007).

The technique that prompted Mazur's (1997) book called Peer Instruction is considered to be one of the leading pedagogical approaches in which meaningful learning can occur when using clicker devices. Peer Instruction (PI) provides a simple and effective model to develop questioning format strategies. In this model, (a) a question is asked, (b) students respond using their clicker, (c) a histogram of their clicker responses is displayed, (d) students discuss with peers for 2-3 minutes to justify responses, (e) a second opportunity to respond is given and ( $f$ ) a histogram is posted a second time. Only then does the lecturer offer the correct response. If the responses from the second histogram reflect limited understanding of the concept, the lecturer can then adapt the lecture to further discussion or provide more examples (Mazur, 1997; Jones et. al, 2012). In cases where initial responses reflect a good understanding ( $75 \%$ correct) of the concept the lecturer is able to move on quickly, or even eliminate content that students have already mastered (Anderson et al., 2011; White et al., 2011). This model is effective in providing a context for students to develop an awareness of their level of understanding and knowledge.

One study from the United States presents positive results for teachers in using clickers, although the researchers had to make significant changes to their teaching practices to see these results (Kolikant et al., 2010). This study used clickers in undergraduate math and science classrooms and results suggest that successful use of clickers does not occur instantaneously in the classroom but is rather a gradual change where the instructors need to overcome various challenges. There are critical teaching and learning moments that provide catalysts for that transition. However, there is still much that we need to learn about these, not only from the perspective of the learners but also from that of the lecturer. It also highlights a gap in the literature whereby common assumptions about students at a university level have remained unstated, allowing for continued perceptions that all students are more confident and competent with using new technologies than their lecturers.

\section{Clickers and large classes}


Research on the use of clickers with questioning methods in large classes has been reported in the work of Mayer and colleagues (2009). When clickers are used in the lecture context, a constructivist approach to learning can be supported by providing regular feedback to students during the lecture setting (Barnett, 2006; Beatty and Gerace, 2009; White et al., 2011). More specifically, strategies can include 10 to 20 minute teaching sessions with a follow up question which requires students to apply their current understanding of course material to formulate an answer via the clicker (Gray and Steer, 2012, Jones et al., 2012, Milner-Bolotin et al, 2010). Caldwell (2007) recommends 2-5 questions for a 50 minute lecture.

By integrating 'clicker questions' into lectures, students are able shift their learning from an 'uptake of information' to an 'application of what has been taught'; meanwhile lecturers are able to gauge levels of understanding to determine future direction of lecture content (Lennox-Terrion and Aceti, 2012). Here, it is notable that, regardless of the correctness of the students' response to a given clicker question, regular testing supports greater retention of information (Anderson et al., 2011; Campbell and Mayer, 2009). This indicates that clicker questions offer a catalyst for inducing student metacognition (defined as knowing about knowing) by developing an awareness of their depth of knowledge, as well as limitations or weaknesses in understanding concepts (Anthis, 2011). When questions are formulated in a manner which requires students to analyse, synthesize or evaluate content, they are facilitating higher order thinking and applying critical thinking to lecture material (Anthis, 2011; Beatty and Gerace, 2009; Trees and Jackson, 2007). This type of clicker questioning can also be implementing with smaller classes.

As can be seen from the above literature review there has been significant research conducted on using clickers in the higher education environment, particularly in the areas of mathematics and science. Although there has been research previously published on the use of clickers in the classroom and there have been several systematic literature reviews (Caldwell, 2007; Fies and Marshall, 2006; Kay and LeSage, 2009; MacArthur and Jones, 2008; Simpson and Oliver, 2007) it has been acknowledged that there is a lack of research in the area of social sciences (Kay and LeSage, 2009). It is possible that due to the different content that is taught in the science and mathematics areas as compared to the social sciences that clicker use and implementation may be quite different and thus this is an area of further research (Kay and LeSage, 2009). There is therefore a need for further research into the use of clickers in the field of social sciences.

Whilst the benefits of the use of clickers in classrooms has been demonstrated, as discussed above further research is needed in order to better understand the process by which the lecturer learns how to incorporate the technology into their pedagogical approach, that is, to look at clickers from the perspective of the teacher as well as from that of the student given the perception, rightly or wrongly, that students are more confident and competent with using new technologies than their lecturers. Much of the literature on the use of clickers has focused on their use in classes with large numbers of students in them and so there is a need to further explore their use in small group settings. Given that experiences of the use of clickers might vary depending on the discipline, and that it has been acknowledged that there is a lack of research in the area of social sciences, there is therefore a need for further research into the use of clickers in the field of social sciences. There is also a need to look at the use of clickers with students at different points in their studies, with the argument being that students who are at an early stage in their higher education studies may be more reluctant to participate in class discussions and engagement through the use of clickers. This is an important point because these students, often in large classes, need to be able to quickly engage with both the course requirements as well as a new learning environment in which they find themselves.

To address the above, the following research questions were developed:

1. How can clickers be integrated into a class setting?

2. How is student learning in class affected through the use of clickers?

3. What are the perceived benefits and challenges of using clickers?

This study traces two parallel themes: first, the personal journey of the academic who taught the class and second, the journey of those students who participated in the use of the clickers. 


\section{Methodology}

This study involved two academics, one coordinating and lecturing in the course and another supporting the use of the clickers, along with one cohort of students. The student cohort was comprised of 200 first year teacher education students at an Australian university studying in the course EDUC1029 Introduction to Education which involved a one hour lecture and a one hour tutorial for 13 weeks. Clickers called ActivExpressions were used. Although the clickers were initially introduced in the weekly lecture, clickers were later introduced to one tutorial class.

Data collection incorporated diary entries by the lecturer and student responses to the use of clickers and reflects both the course coordinator's journey through the process of introducing this new technology to her students and changing students' responses as they engage with this technology. This course is a compulsory course in pre-service teacher education and it introduces students to particular themes as well as stimulating students to think about contemporary educational issues and examine their own preconceived notions of schooling, education and how we learn. An important component of the course is to encourage students to share their reflections on their own educational experiences. Ethics approval was obtained by the university prior to the study and students subsequently gave their permission through the approved procedures with data being collected in August to October, 2011.

Data were collected through the use of case study research, which has the advantage of being strongly grounded allowing attention to focus on the contextually unique features (Cohen et al., 2000). The initial phase involved a trial during a lecture of a computer software program that was developed by Promethean. This software, called ActivEngage, was placed into the Blackboard learning environment from August to October 2011, for students to download onto their laptops before the lecture. Students were given the information and instructions via Blackboard about how to download ActivEngage prior to the lectures. Students were also supported through the use of two experienced helpers (post graduate students) who spent time in the common room so that the students in the course could go to them for help with downloading the file. The helpers were available for a total of eight hours in the common room.

After introducing to the entire cohort to the clickers, one tutorial class was chosen for the rest of the study. Data were collected in numerous ways from one tutorial group of 20 students. These included clicker questions pertaining not only to the topic at the time, but questions about how comfortable the students felt using the technology and if they had used it previously. Students were asked on a six point scale from 'very unsure' to 'very confident'. The students were also asked to complete an online questionnaire at the end of the semester with a combination of closed and open questions. Students' responses to the weekly topics were also made available in Blackboard for all students as it was thought this may help with their assignments. Another way of evaluating the usefulness of clickers was to ask students if they used the responses from throughout the semester to assist with the final assignment, as responses had been placed into Blackboard for all students in the course. Students were also asked about using the clickers in the class and were asked to respond. Of the 20 students asked to complete the questionnaire 12 participated in it. The clicker questions on the topic each week were also analyzed by the researchers to investigate the types of responses the students were giving and how these responses allowed the students to engage differently with the course than if the ActivExpressions were not being used.

Data were also collected by the academic involved. This academic was the course coordinator. This was recorded in the form of regular diary entries and contributes to the data included (presented as indented quotations). Data was systematically analysed through its examination of the recurring themes and explored through the use of categories that related to the research questions. Once these categories were assigned, the analysis actually relied heavily on description rather than inference. The data was analysed by both the academics involved in the project.

\section{Results}

How can clickers be integrated into a class setting?

In preparation for the first lecture which would include the use of clickers eight hours were allocated for two experienced helpers to support students' set up ActivEngage prior to the first lecture. This was 
publicized widely. However, only four of the 200 enrolled students utilized this help at the time. Thus, in the first lecture that ActivEngage was used it meant that many students had not downloaded the file or put in the settings, so where the 'registration' process should have taken only two minutes, in effect it took much longer, even though students were aware of the fact they needed to complete part of the process prior to time. Once the registration process was completed there were also other technological problems which led to reduced teaching time and, therefore, the initial experience was deemed not to have been a success. The following extract reflects not only the risks of student disengagement, but also the academic's disengagement when the technology does not work as intended:

The initial trial during the lecture met my worst fear, despite having support staff present. A collection of small incidents conspired against us, almost cementing my feelings of helplessness with the latest 'gimmicks' that seem to divert us from the actual task of teaching and learning.

Results have been significant in terms of what they tell us about incorporating new technologies into teaching, perceived and real obstacles that may limit the enthusiasm of the participants, and the possibilities of enhancing more effective dialogue between students and lecturers. The following diary entry by the academic highlights these points clearly. In the following extract the lecturer reflects on the first lecture when the technology was not able to support her adequately:

The following day, we quickly recovered: Plan B - A smaller trial with only one tutorial group and a smaller number of questions, the aim being that I become familiar and comfortable with the programme first so that I can stay focussed on the students.

How is student learning in class affected through the use of clickers?

Many students were initially unsure about how to use the clickers, some expressing 'not very confident' at the beginning of the tutorial. Responses were recorded by asking the students at the beginning and end of the tutorial, and were anonymous. Despite some initial nervousness on the part of the students, the ActivExpression devices proved easy to use, with more students rating themselves as 'confident' at the end of the first tutorial class.

The increase in student confidence was noted in feedback from student responses, with most students shifting quickly from 'unsure' to 'confident' or 'very confident' in relation to using the clickers through the course of the study. Students remained unidentified as they keyed in their responses to questions asked during the tutorials. In this way building student confidence was further enhanced because the lecturer was able to keep student responses anonymous, allowing them to express uncertainty about ideas contained in the course readings, or to express a different point of view, ensuring their participation within a supportive environment. Over the course of several weeks, the academic also developed her own level of confidence and skill. In a later diary entry it was noted:

Today we kept right on time and everything worked well. I was able to pick up on some of the points students made and start discussions which responded more directly to what the students needed at the time.

As the study continued students also began to offer comments about their own learning. Since much of the tutorial discussion focused on responses to questions related to weekly readings, it was essential that students prepare the readings before their class. As one student commented in a question using the clickers that using the clickers to respond to the questions "did actually make me read the readings". Through using the clickers in class it was easy to see when students expressed similar concerns or questions, therefore the discussion could be guided according to the responses that were given. In other responses students commented:

The learner response system questions helped me to know how well I was learning the material. [Student P]

By using the learner response system in this class, I got feedback on my understanding of class material. [Student D]

It was good to hear other people's views on the topic, especially those people who wouldn't normally raise their hand to answer a question. [Student S] 
Students also showed considerable interest in reading the responses by fellow students as they were displayed on the screen and everyone became aware that they had contributed to the 'collection' of ideas.

In later weeks, students were allocated a clicker number which enabled the lecturer to know who had responded to the questions. This was a small shift, removing anonymity of students in relation to the academic's knowledge of their responses, while still maintaining a degree of anonymity within the class as a whole. This small change nevertheless contributed to a much greater and more sophisticated engagement of students with the course material. The transition in students' perceptions was observed, as was that they responded positively to the use of the clickers, and also provided increasingly confident and more meaningful responses to the concepts discussed over the duration of the course. As the academic noted in the diary:

Great responses today! It seems that students are over the initial novelty factor but not only that, they are offering some in-depth understandings of the readings that I don't think they would have volunteered aloud. I am starting to get an understanding of how I might use these inclass responses and help students prepare for their written assignments (i.e. post them up on Blackboard so they can use them to help with their analysis).

With the students' growing comfort with using the clickers, and with their increasingly sophisticated responses to the course materials, it was decided to post their responses to in-class discussions on the course Blackboard site and they were encouraged to draw on these to help them with their written assessment pieces. The academic had commented that students often found it difficult to develop the analysis and discussion sections of their writing when they are alone away from their classes, but having their tutorial discussions recorded via the clickers and then made available via Blackboard, students were able to recall the discussions with these prompts and build on work they had already started collectively. Responses uploaded to Blackboard were also made available to the large cohort of students (200) in the course, to assist with further discussions or as a resource for their written tasks.

What are the perceived benefits and challenges of using clickers?

There was some initial concern about whether the clickers would in fact lead to students engaging more with the course. At the end of the course the students were asked to reflect on their experience using the clickers by completing an online questionnaire. In the final questionnaire, eight students (of the 11 who completed the question) agreed with the statement "I thought about the questions posed carefully and seriously and thought about the answers before voting during the tutorials." This also suggests that the students were not in a hurry to complete the answers, even though they perceived the class was pushed for time by including the use of the clickers when the short 50 minute classes also had to accommodate student presentations.

Another example of one of the tutorial questions formulated for response using the clickers was "what do you think were the main challenges faced by the principals at the three schools mentioned in the article?" The clickers, in essence, could only be used to provide brief responses. During the course, however, students began to increase their ability to provide succinct and more focused responses while still giving meaningful responses that would simultaneously spark further class discussion. Students demonstrated increasing competence at expressing their ideas; this was paralleled by the academic's increasing ability to formulate appropriate questions that enabled students to give meaningful, yet succinct, responses.

Later questions reflected the confidence in adapting appropriate questions with the technology, as discussion starters. An example of this is the question "reflecting on the readings we have discussed and the lectures you have attended, how do you think the issues raised in this course relate to your own school experiences?" Previously, the academic reported that there would have been a 'wait time' while students think about the question, then often only a small number of students would respond. By using the clickers for this type of reflective question students were able to 'bypass' any degree of shyness they may have been feeling and still provide a more personal, yet anonymous, response for the whole group to discuss. Another question type included "how is parent participation a social justice issue?" This question was designed as a way of feeding into group discussions to analyze their weekly 
readings. Using the clickers with this type of question served the purpose of both a 'brainstorming' activity and the opportunity to summarize and review previous discussions.

\section{Discussion and conclusion}

This study initially set out to investigate the implementation of clickers in an education setting with a large class. Much has been researched pertaining to large classes and clicker implementation (Bachman and Bachman, 2011; Beatty and Gerace, 2009; Koenig, 2010, Laxman, 2011) and this study has added to this by using clickers in a small class situation and investigating student engagement and student participation in class both from the perspective of the students and also from the perspective of faculty.

The findings of this study revealed common assumptions at a university level concerning the relationship between students and technologies, as well as a perceived difference between students and lecturer. It can easily be assumed that students, because of their youth, have a confidence and comfort with using all new technologies (Prensky, 2004, 2006). However, this assumption was not supported in this study. Further, the diversity of student backgrounds incorporates a diverse range of individual student experiences when using a range of technologies. Therefore, an assumption of student confidence and familiarity with new technologies can not only be misleading for lecturers and tutors but can also contribute to students' own lack of confidence particularly if they do not feel competent with certain technologies. This may lead to a level of discomfort where some students simply do not respond in class, rather than risk their 'lack' of IT skills being noticed. In keeping with Premkumar and Coupal's (2008) reminder that the focus needs to remain on pedagogy, teacher interpretations of 'quiet' students can be even more problematic as they attempt to determine whether this is due to limited understanding of course content or simply lack of confidence with the technology.

Students' interest in reading contributions by their peers during the tutorials where clicker responses were presented and discussed suggest that using the clickers not only promoted more class participation and engagement with the course materials but also potential to quickly assess student understanding of the content they are discussing. This is consistent with the findings of Massingham and Herrington (2006) in their study on student attitudes, participation, performance and attendance in tutorials and lectures. This process allowed the lecturer to immediately follow through with more indepth discussions that could flow comfortably from a particular set of student responses displayed on the screen.

One of the most significant findings from this study related to the lecturer's ability to adapt questions to the technology of the clickers itself. The greatest challenge with clickers for the lecturer was how to phrase questions that would allow students to demonstrate their understanding. The pedagogical approach of the lecturer incorporated mostly open-ended high-order questions. As demonstrated in the review of literature, most research focuses on the use of clickers in math and science classes where short-answer responses can help students and lecturers monitor progress relatively quickly. A common use of clickers therefore has been to elicit mostly closed, low-order responses. With this study, the application of the clickers has been pushed by investigating their use in disciplines where there is use of open-ended questions.

At the end of the study both the cohort of student participants and the academic concluded that the use of clickers was a valuable tool to use in tutorials. Anecdotal feedback given in the final tutorial by students suggests that they may not be effective for use in every tutorial due to the limitations of a onehour tutorial and that too many questions which relied on clicker responses could take time away from lengthier group discussion. From the academic's perspective, they felt more confident in using both the technology and the ability to adapt her teaching to a more engaging format for students that would ensure a higher degree of participation by all students. It was also found that by incorporating students' responses in tutorials as a resource, by posting their clicker responses to Blackboard, the lecturer was able to demonstrate that their contributions were valued and assist students in continuing their analysis when alone on their written tasks. The above results suggest there was some trial and error that occurred by the lecturer with the implementation and use of clickers. This is consistent with the findings by Kolikant et al. (2010), who argue that the gradual process of overcoming challenges needs to be managed carefully. 
The results of this study provide support for the argument that it is beneficial to try new technologies with a class and that even though things may not go smoothly it is worth the effort to continue on and solve any problems arising as student's will benefit from the technological success (Barnett, 2006). This study's initial findings have demonstrated that students became more confident and thoughtful in relation to providing responses to questions during class discussions. It also found that students were more likely to complete the reading prior to class as they knew they would be required to answer questions in class. This study sends a clear message about the levels of support that are required when teaching and it also points to the need for careful scaffolding in order to maximise student, and lecturer, participation. Although using technology can provide some difficulties this study demonstrates the benefits of persisting. The resourcing and updating of university lecture room's needs to be accompanied by pedagogies that reflect the research on changing student needs. Such a process takes both time and technical support, along with a preparedness to experiment with the technology in order to search for ways that keep teaching and learning central, and assist the student/teacher relationship.

This project was a small investigatory study that had a 13 week timeframe and a small cohort of participants. These factors form the limitations of the study and would benefit from being repeated with a larger number of students in small classes. Possible future research would benefit the field and include areas such as students bringing their own devices to use with the clickers on them and studies on digital reluctants implementing clickers successfully with large classes. Other limitations include the study being conducted at only one university with students who are in their first year of higher education and that they were from a particular discipline. That students were for the most part Australian limits generalisability and so future work needs to look at other cultural contexts given that these impact aspects of both learning and teaching.

It has been suggested by Kay and LeSage (2009) that further research needs to be completed as it is unclear if the use of clickers is best suited to courses that have greater technical aspects. Further research pertaining to open ended questions and large classes would be advantageous as would research in various different fields. Whilst this study supports much of the positive research about the use of clickers, one of the most significant contributions lies in the 'mapping out' of the process which gives transparency to the ways in which educators align their pedagogical approaches with the use of this technology.

\section{References}

Anderson LS, Healy AF, Kole JA and Bourne LE (2011) Conserving time in the classroom: the clicker technique. Quarterly Journal of Experimental Psychology 64(8): 1457-1462.

Anthis K (2011) Is it the clicker, or Is it the question? Untangling the effects of student response system use. Teaching of Psychology 38(3): 189-193.

Bachman L and Bachman C (2011) A study of classroom response system clickers: Increasing student engagement and performance in a large undergraduate lecture class on architectural research. Journal of Interactive Learning Research 22(1): 5-21.

Blood E and Neel R (2008) Using student response systems in lecture-based instruction: Does it change student engagement and learning? Journal of Technology and Teacher Education 16(3): 375-383.

Barnett J (2006) Implementation of personal response units in very large lecture classes: Student perceptions. Australasian Journal of Educational Technology 22(4): 474-494.

Beatty I and Gerace W (2009) Technology-enhanced formative assessment: A research-based pedagogy for teaching science with classroom response technology. Journal of Science Education and Technology 18(2): 146-162.

Caldwell JE (2007) Clickers in the large classroom: Current research and best-practice tips. CBE Life Sciences Education 6(1): 9-20.

Campbell J and Mayer RE (2009) Questioning as an instructional method: Does it affect learning from lectures? Applied Cognitive Psychology 23(6): 747-759.

Cohen L, Manion L and Morrison K (2000) Research Methods in Education, London: RoutledgeFalmer. Dallaire DH (2011) Effective use of personal response "clicker" systems in psychology courses. Teaching of Psychology 38(3): 199-204.

Fies C and Marshall J (2006) Classroom response systems: A review of the literature. Journal of Science Education and Technology 15(1): 101-109.

Gray K, and Steer DN (2012) Personal response systems and learning: It is the pedagogy that matters, not the technology. Journal of College Science Teaching 41(5): 80. 
Hall RH, Collier HL, Thomas ML and Hilgers MG (2005) A student response system for increasing engagement, motivation, and learning in high enrollment lectures. Americas Conference on Information Systems (AMCIS) 2005. Paper 255. Omaha, NE, USA August 11th-14th 2005.

Hoekstra A, and Mollborn S (2011) How clicker use facilitates existing pedagogical practices in higher education: Data from interdisciplinary research on student response systems. Learning, Media and Technology 1-18, iFirst Article:1-18.

Jones ME, Antonenkot PD and Greenwood CM (2012) The impact of collaborative and individualized student response system strategies on learner motivation, metacognition, and knowledge transfer. Journal of Computer Assisted Learning. 28(5): 477-487.

Kay, RH and LeSage A (2009) Examining the benefits and challenges of using audience response systems: A review of the literature. Computers \& Education. 53: 819-827.

Koenig K (2010) Building acceptance for pedagogical reform through wide-scale implementation of clickers. Journal of College Science Teaching 39(3): 46.

Kolikant YB-D, Drane D and Calkins S (2010) "Clickers" as catalysts for transformation of teachers. College Teaching 58(4): 127 - 135.

Laxman K (2011) A study on the adoption of clickers in higher education. Australasian Journal of Educational Technology 27(8): 1291-1303.

Lennox Terrion J and Aceti V (2012) Perceptions of the effects of clicker technology on student learning and engagement: a study of freshmen Chemistry students. Research in Learning Technology 20(Journal Article): 1-11.

MacArthur JR and Jones LL (2008) A review of literature reports of clickers applicable to college chemistry classrooms. Chemistry Education Research and Practice 9, 187-195.

Massingham P and Herrington T (2006) Does attendance matter? An examination of student attributes, participation, performance and attendance. The Journal of University Teaching \& Learning Practice. 3(2): 83-103.

Massoud A, Iqbal U, Stockley D and Noureldin A (2011) Using blended learning to foster education in a contemporary classroom. Transformative Dialogues: Teaching \& Learning Journal 5(2): 1-11.

Mayer RE, Stull A, DeLeeuw K, Almeroth K, Bimber B, Chun D, Bulger M, Campbell J, Knight A and Zhang $\mathrm{H}$ (2009) Clickers in college classrooms: Fostering learning with questioning methods in large lecture classes. Contemporary Educational Psychology 34: 51-57.

Mazur, E (1997). Peer Instruction: A User's Manual. Upper Saddle River, NJ: Prentice Hall.

Milner-Bolotin M, Antimirova T and Petrov A (2010) Clickers beyond the first-year science classroom. Journal of College Science Teaching 40(2): 14-18.

Murphy KL, Picione $\mathrm{J}$ and Holme TA (2010) Data-driven implementation and adaptation of new teaching methodologies. Journal of College Science Teaching 40(2): 80-86.

Powell S, Straub C, Rodriguez J and VanHorn B (2011) Using clickers in large college psychology classes: Academic achievement and perceptions. Journal of the Scholarship of Teaching and Learning 11(4): 1-11.

Premkumar K and Coupal C (2008) Rules of engagement - 12 tips for successful use of "clickers" in the classroom. Medical Teacher 30:2 146-149.

Prensky M (2004) The emerging online life of the digital native: What they do differently because of technology and how they do it. Available at: http://www.marcprensky.com/writing/PrenskyThe_Emerging_Online_Life_of_the_Digital_Native-03.pdf

Prensky M (2006) Adopt and Adapt: 21st century schools need 21st century technology. Edutopia. Available at: marcprensky.com

Simpson V and Oliver, M (2007) Electronic voting systems for lectures then and now: A comparison of research and practice. Australasian Journal of Educational Technology 23(2): 187-208.

Strasser N (2010) Who wants to pass Math? Using clickers in calculus. Journal of College Teaching and Learning 7(3): 49-52.

Sweeney J, O'donoghue T and Whitehead C (2004) Traditional face-to-face and web-based tutorials: A study of university students' perspectives on the roles of tutorial participants. Teaching in Higher Education 9(3): 311-323.

Trees AR and Jackson MH (2007) The learning environment in clicker classrooms: student processes of learning and involvement in large university-level courses using student response systems. Learning, Media and Technology 32(1): 21-40.

White PJT, Delaney DG, Syncox D, Akerberg OA and Alters B (2011) Clicker implementation models. EDUCAUSE Quarterly 34(4). Retrieved from: www.educause.edu/ero/article/clicker-implementationmodels 
Yourstone SA, Kraye HS and Albaum G (2008) Classroom questioning with immediate electronic response: Do clickers improve learning? Decision Sciences Journal of Innovative Education 6(1): 7588. 